\title{
THE EFFECT OF THYROID DISEASE ON CALCIUM METABOLISM IN MAN ${ }^{1}$
}

\author{
BY STEPHEN M. KRANE, GORDON L. BROWNELL, JOHN B. STANBURY, AND \\ HELEN CORRIGAN
}

\section{(From the Medical Services of the Massachusetts General Hospital and the Department of Medicine of the Harvard Medical School, Boston, Mass.)}

(Submitted for publication October 31, 1955; accepted April 24, 1956)

Abnormal thyroid function profoundly alters calcium metabolism. In 1929, Aub, Bauer, Heath, and Ropes (1) demonstrated in patients on constant low calcium diets that urinary and fecal excretion of calcium and phosphorus is frequently increased in hyperthyroidism and lower than normal in myxedema. These changes could not be ascribed to elevation of metabolism per se (1) acidosis (2) or vitamin D deficiency (3); they were observed even in the absence of the parathyroid glands $(4,5)$. In addition, roentgenographic evidence of skeletal demineralization has been described in patients with thyrotoxicosis (6).

The conventional balance techniques which have been used in the study of calcium metabolism in thyroid disease measure only net effects: they do not measure the processes of deposition and resorption of calcium. An indication of the skeletal turnover of calcium, however, can be obtained from serial observations of the specific activity of radioactive calcium $\left(\mathrm{Ca}^{45}\right)$ in blood and urine after intravenous injection $(7,8)$.

The present study was designed to define the alterations in calcium metabolism in thyroid disease in man by using $\mathrm{Ca}^{45}$ and the technique of isotope dilution. Observations have been made in euthyroid, hyperthyroid, and myxedematous subjects, and, for purposes of comparison, in additional euthyroid patients with Paget's disease and with hypoparathyroidism.

\section{MATERIALS AND METHODS}

All patients (Table I) were on the metabolic ward and were ambulatory throughout the study. Diets, which were constant and of neutral ash, contained from 0.08 to 0.23 grams of calcium per day (Table II). In order to avoid tetany, the two hypoparathyroid subjects were given 0.31 and 0.57 grams, respectively, of calcium

1 Aided by grants AT (30-1) 667 and AT (30-1) 1755 from the Atomic Energy Commission and A(446) C from the United States Public Health Service. in their diets per day. Fluid intake was maintained at 2,000 to $2,500 \mathrm{ml}$. per day. Complete collections of urine and stool were begun after six days on the fixed diet. A three-day control collection of urine and feces was obtained prior to the administration of $\mathrm{Ca}^{\text {s.5 }}$.

The stock solution of $\mathrm{Ca}^{45} \mathrm{Cl}_{2}{ }^{2}$ was acidified with concentrated $\mathrm{HCl}$, added to 0.9 per cent $\mathrm{NaCl}$ solution to give a final concentration of approximately $0.5 \mu \mathrm{c}$ per $\mathrm{ml}$. saline at a $\mathrm{pH}$ of 6 , and autoclaved. Five to seven microcuries were injected from a calibrated syringe into an antecubital vein one hour before breakfast. Blood samples were obtained by venipuncture from the opposite arm at frequent intervals. Fractional urine collections were made for the first three days following injection, and daily thereafter. Stool collections were made

TABLE I

Clinical data

\begin{tabular}{|c|c|c|c|}
\hline Name & Age & Sex & Diagnosis \\
\hline R. P. & 50 & $\mathbf{M}$ & $\begin{array}{l}\text { Coronary heart disease; hyperurice- } \\
\text { mia (A.S.H.D.)* }\end{array}$ \\
\hline $\begin{array}{l}\text { Wa. W. } \\
\text { F. W. (1) }\end{array}$ & $\begin{array}{l}26 \\
18\end{array}$ & $\begin{array}{l}\mathbf{M} \\
\mathbf{M}\end{array}$ & $\begin{array}{l}\text { reich's ataxia (Fr.A.) } \\
\text { rthyroid (diffuse goiter) (Thyr- }\end{array}$ \\
\hline (2) & 19 & & $\begin{array}{l}\text { Euthyroid, hypoparathyroid, } 1 \text { yr. } \\
\text { following thyroidectomy (Hypo- } \\
\text { parathyr. after Rx.) }\end{array}$ \\
\hline L. S. (1) & 31 & $\mathbf{F}$ & $\begin{array}{l}\text { Hyperthyroid (diffuse goiter) (Thyr- } \\
\text { tox.) }\end{array}$ \\
\hline (2) & 31 & & $\begin{array}{l}\text { Early myxedema ( } 4 \text { months follow- } \\
\text { ing thyroidectomy) (Myx. after } \\
\text { Rx.) }\end{array}$ \\
\hline C. L. & 38 & $\mathbf{F}$ & $\begin{array}{l}\text { Hyperthyroid (diffuse goiter) (Thyr- } \\
\text { tox.) }\end{array}$ \\
\hline J. B. & 26 & $\mathbf{M}$ & $\begin{array}{l}\text { Hyperthyroid (diffuse goiter) (Thyr- } \\
\text { tox.) }\end{array}$ \\
\hline W. W. (1) & $\begin{array}{l}42 \\
42\end{array}$ & $\mathbf{F}$ & $\begin{array}{l}\text { Myxedema (Myx.) } \\
\text { Euthyroid (4 months on treatment) } \\
\text { (Normal after Rx.) }\end{array}$ \\
\hline B. M. (1) & $\begin{array}{l}39 \\
39\end{array}$ & F & $\begin{array}{l}\text { Myxedema (Myx.) } \\
\text { Euthyroid (5 months on treatment) } \\
\text { (Normal after Rx.) }\end{array}$ \\
\hline A. W. & 67 & $F$ & $\begin{array}{l}\text { Paget's disease of bone (Osteitis De- } \\
\text { formans) (Paget's dis.) }\end{array}$ \\
\hline O. H. & 59 & $\mathbf{F}$ & $\begin{array}{l}\text { Paget's disease of bone (Osteitis De- } \\
\text { formans) (Paget's dis.) }\end{array}$ \\
\hline E. N. & 41 & $\mathbf{F}$ & $\begin{array}{l}\text { Hypoparathyroid, } 4 \text { years following } \\
\text { thyroidectomy (Hypoparathyr.) }\end{array}$ \\
\hline
\end{tabular}

* Abbreviations to be used in all tables.

2 Obtained from Oak Ridge. $\mathrm{Ca}^{\text {* }}$ has only a beta ray (M.E.V. $=0.26$ ) and a half-life of 152 days. 


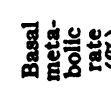

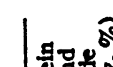

tint

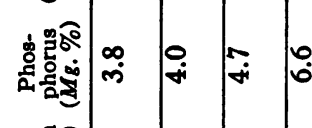

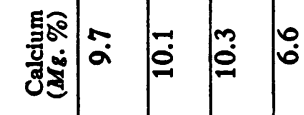

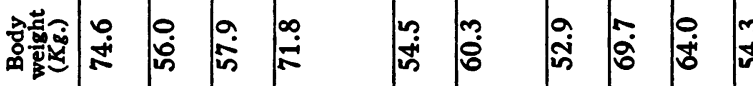

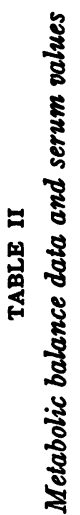

|

สิ

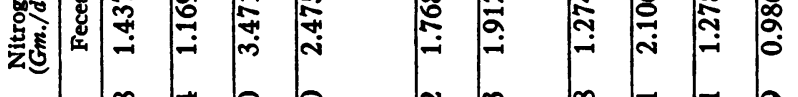

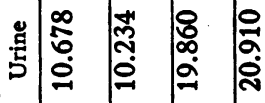

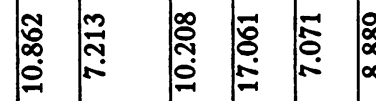

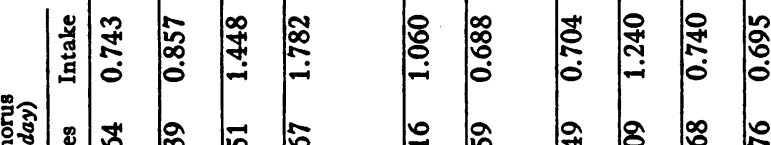

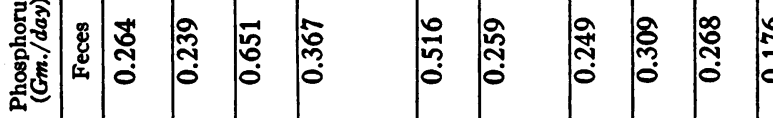

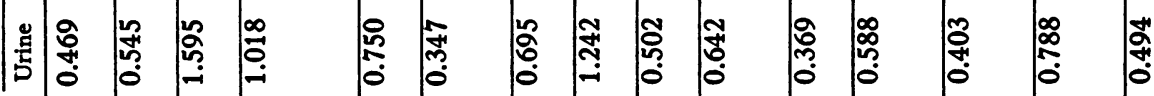

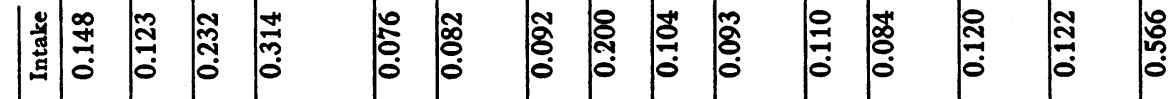

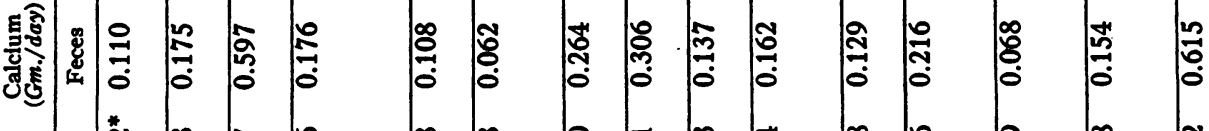

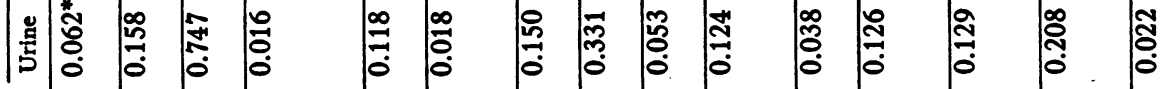

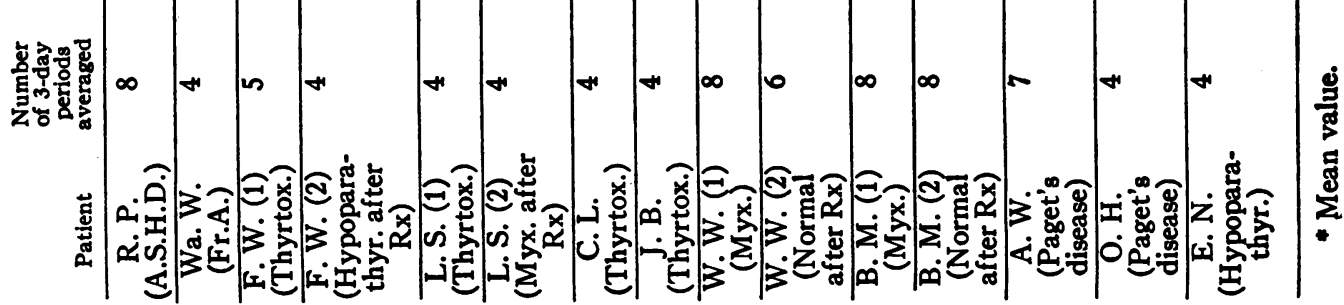


in three-day periods. An aliquot of the solution used for injection was taken for the standard. The amount of stable calcium $\left(\mathrm{Ca}^{\text {to }}\right)$ included in each injection ranged from 1 to $6 \mathrm{mgm}$. After giving the $\mathrm{Ca}^{\mathrm{w}}$, collections were made for times ranging from 9 to 22 days for the various patients. If a previous study had been done, control collections were assayed for radioactivity prior to the administration of the second tracer of $\mathrm{Ca}^{25}$.

Stable calcium $\left(\mathrm{Ca}^{\infty}\right)$ was determined by the method of Fiske and Logan (9). The results of analysis of duplicate samples agreed within \pm 3 per cent of the mean. Phosphorus ${ }^{3}$ was determined by the method of Fiske and Subbarrow (10) and nitrogen according to the macromethod of Kjeldahl. Aliquots of urine $(200 \mathrm{ml}$.) were acidified with $4 \mathrm{ml}$. of concentrated $\mathrm{HCl}$. The 3-day stool collections (obtained without a marker) were mixed in a Waring Blendor, and made up to volume with distilled water. For calcium and phosphorus analyses, duplicate 200-ml. aliquots of the blended and diluted fecal samples were dried for 2 to 3 days in a steam oven and then ashed in an electric muffle furnace at $550^{\circ} \mathrm{C}$. overnight. The ash was dissolved in concentrated $\mathrm{HCl}$ and distilled water. Nitrogen analyses of the feces were performed directly on unashed aliquots of the blended and diluted fecal samples.

$\mathrm{Ca}^{43}$ was determined as follows : $44 \mathrm{ml}$. of trichloracetic acid (20 per cent) and $8 \mathrm{ml}$. of distilled water were added to $2.4 \mathrm{ml}$. of serum, the sample centrifuged, and the $\mathrm{Ca}^{25}$ determination performed on the supernatant. Complete recovery of $\mathrm{Ca}^{{ }^{25}}$ added to human serum in vitro was achieved. Analyses of $\mathrm{Ca}^{\mathrm{s}}$ in urine and feces were made on acidified specimens which had been dried and ashed, and the ash dissolved in $\mathrm{HCl}$ and distilled water. After analysis for the stable calcium of the sample, stable calcium was added as $\mathrm{CaCl}_{2}$ to give a final concentration of $6.0 \mathrm{mgm}$. per sample in all specimens. From a self-absorption curve this concentration was found to be optimal for sensitivity and reproducibility of sample measurements. Calcium was then precipitated as calcium oxalate by the addition of saturated ammonium oxalate solution. The solution was made alkaline by the addition of dilute ammonium hydroxide and then adjusted to $\mathbf{a} \mathrm{pH}$ of 5.4 with 2.5 per cent oxalic acid, using an alcoholic solution of methyl red as indicator. After adding Triton $\mathrm{X}-100^{5}$ ( 0.1 per cent) as a detergent, the samples were filtered over sintered glass on filter paper discs, $24 \mathrm{~mm}$. diameter (Schleicher and Schuell No. 576), which were cemented to copper discs with polystyrene coil dope.

The discs from initial studies were assayed for $\mathrm{Ca}_{2}{ }^{\mathrm{s}} \mathrm{um}$ der a thin $\left(<1.9 \mathrm{mgm}\right.$. per cm. $\left.{ }^{2}\right)$ mica end-window G.M. tube connected to an automatic sample changer (Tracerlab). In later studies, a gas-flow counter was used which

3 The authors are indebted to the hospital chemistry laboratory under Dr. Charles Dutoit and Miss G. Margaret Rourke for the phosphorus and nitrogen analyses.

4 This method was developed by Dr. C. J. Maletskos of the Massachusetts Institute of Technology.

5 Obtained from Rohm and Haas Co., Philadelphia 5, Pennsylvania. increased sensitivity from 250,000 to 500,000 counts per minute per microcurie. Each of the duplicate samples was measured three times to an accumulation of 4,096 counts. The standard was assayed with each run. The maximum variation in accumulated counts of duplicate samples was \pm 6 per cent of the mean. The usual variation was \pm 3 per cent. Recorded radioactivity of the samples was at least twice background.

The data for $\mathrm{Ca}^{45}$ are expressed as per cent administered dose. Specific activity, as per cent of administered dose of labeled calcium per gram of calcium, was calculated for each sample. ${ }^{6}$

\section{METHODS OF ANALYSIS}

Inspection of the semi-logarithmic plot of specific activities in urine and serum against time suggested that the curves could be resolved into a series of three or possibly more decreasing exponential functions. This was of interest because of the possibility that each function represented a discrete calcium compartment within the body. The data were treated with this assumption in view.

Analysis of exponents: The method of curve analysis is illustrated in Figure 1 where serum and urine specific activities of an hyperthyroid subject are plotted against time in days. Serum specific activities are plotted for the first day. Since the radioactivity of many serum samples was low by 24 hours following the administration of $\mathrm{Ca}^{\mathrm{s}}$, urine specific activities are plotted from the second day onward. The data of all subjects have been treated in an identical manner. In Figure 1 (A) are plotted the observed specific activities from 0 to 9 days. The data from 1.25 to 8.5 days appeared to follow a single exponential function. By the method of least squares a fit of this range of the data to the function $A_{2} e^{-k s t}$ yielded the solid line of Figure 1 (A) $\left(A_{3}\right.$ is specific activity extrapolated to zero time, $k_{8}$ is the rate constant in fraction per day, and $t$ is time in days). When this function was subtracted from the observed data, the values in Figure 1 (B) were derived. An analysis by least squares of the data between 0.13 and 0.67 days yielded the solid line in Figure 1 (B). When this line of slope $k_{2}$ was extrapolated to zero time, the specific activity value of $A_{2}$ was obtained. This line subtracted from the remaining data of Figure 1 (B) yielded the points in Figure 1 (C). The solid line in Figure 1 (C) is the least squares fit of those data with slope $k_{1}$, and when extrapolated to zero time gives $A_{1}$. Thus, the data are analyzed in the form:

$$
\text { Specific activity }=A_{1} e^{-k_{1} t}+A_{2} e^{-k_{2} t}+A_{3} e^{-k_{3} t} \text {. }
$$

Compartments: The size of each "compartment" (Q) was obtained by dividing 100 per cent (the quantity of labeled calcium at zero time) by the extrapolated specific

"The term "labeled calcium" refers to that quantity of calcium which was initially given to the patient as a tracer dose marked with radioactive calcium. This quantity is independent of radioactive decay. 


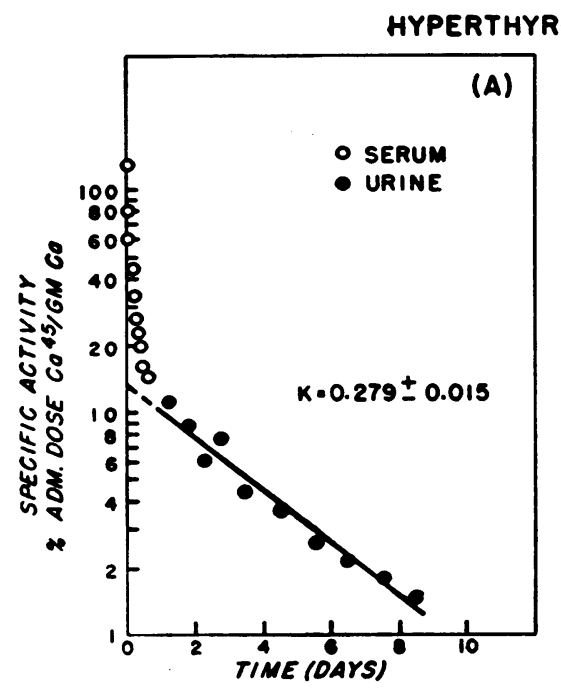

010 pt. L.S.
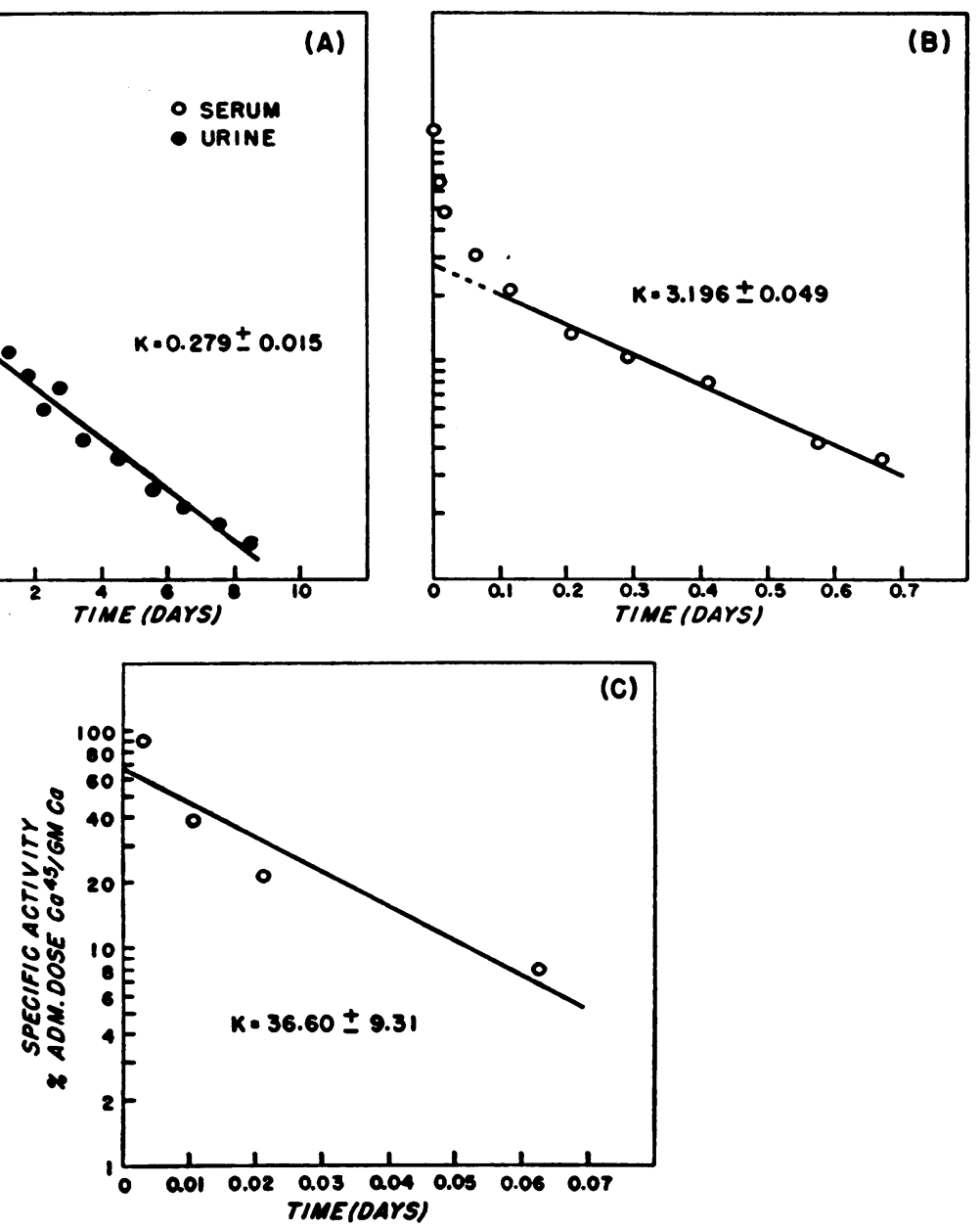

Fig. 1. Illustration of the Method of Analysis of Exponential Functions of Specific Activity Curve Plotted Semi-Logarithmically Versus Time

The data obtained from subject $L$. S.(1) (hyperthyroid) are used as examples. Note the different time scale for (A), (B) and (C). The specific activity values on the ordinate are the same for (A), (B) and (C). The solid line in (A) has the slope $k_{3}$ which extrapolated to zero time yields $A_{8}$; the solid line in $(B)$ has the slope $k_{2}$ and intercept $A_{2}$; the solid line in (C) has the slope $k_{1}$ and intercept $A_{1}$. For further explanation, see the text.

activity value (A) for each function. For the third compartment $\left(Q_{3}\right)$ this equals $\frac{100 \%}{A_{3}}$; for the second $\left(Q_{2}\right)$, $\frac{100 \%}{A_{3}+A_{2}} ;$ for the first $\left(Q_{1}\right), \frac{100 \%}{A_{3}+A_{2}+A_{1}}$. This analysis is rigorously correct only when the size of the compartments (Q) increases and the flow (kQ) decreases from one to the next compartment.

Calcium "pool": If specific activity

$$
\text { (i.e., } \frac{\% \text { administered dose } \mathrm{Ca}^{45}}{\text { gram } \mathrm{Ca}^{10}} \text { ) }
$$

is known at time $t$, and the quantity retained in the body (100 per cent of administered $\mathrm{Ca}^{43}$ minus per cent ex- creted) is known, the per cent retained at time $t$ divided by the specific activity at time $t$ is the calcium "pool" at time $t$. The concept of a calcium "pool" makes no assumption based on the shape of the curves, but reflects the fact that a lower specific activity at any time means a larger mass of dilution. Calcium "pool" curves were derived from the ratio between the curve of labeled calcium retention and the specific activity curve for the various patients.

The analysis of calcium metabolism presented here assumes that the calcium is first present in a small compartment with a rapid flow to and from a larger second compartment. This flow accounts for the initial rapid 


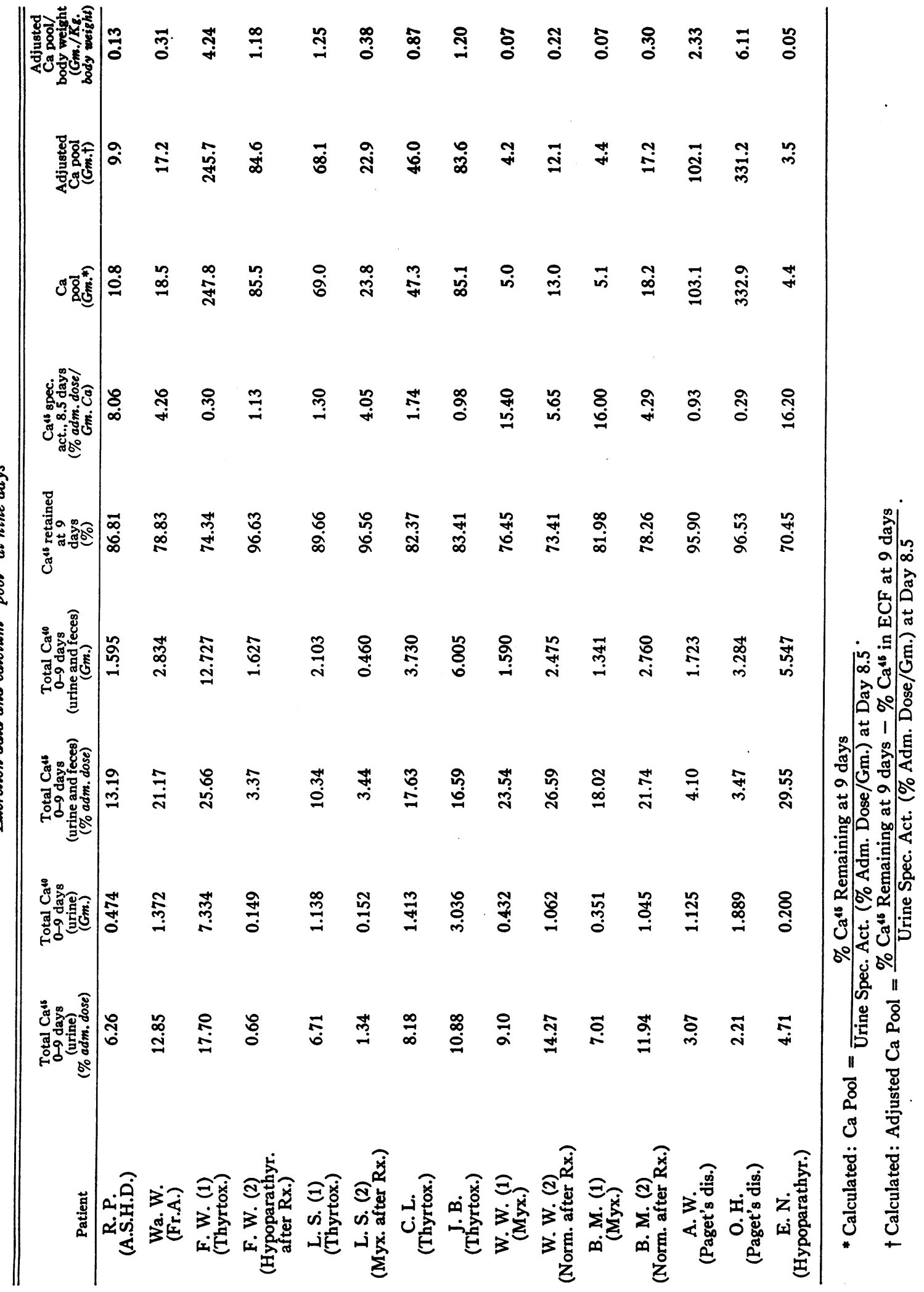




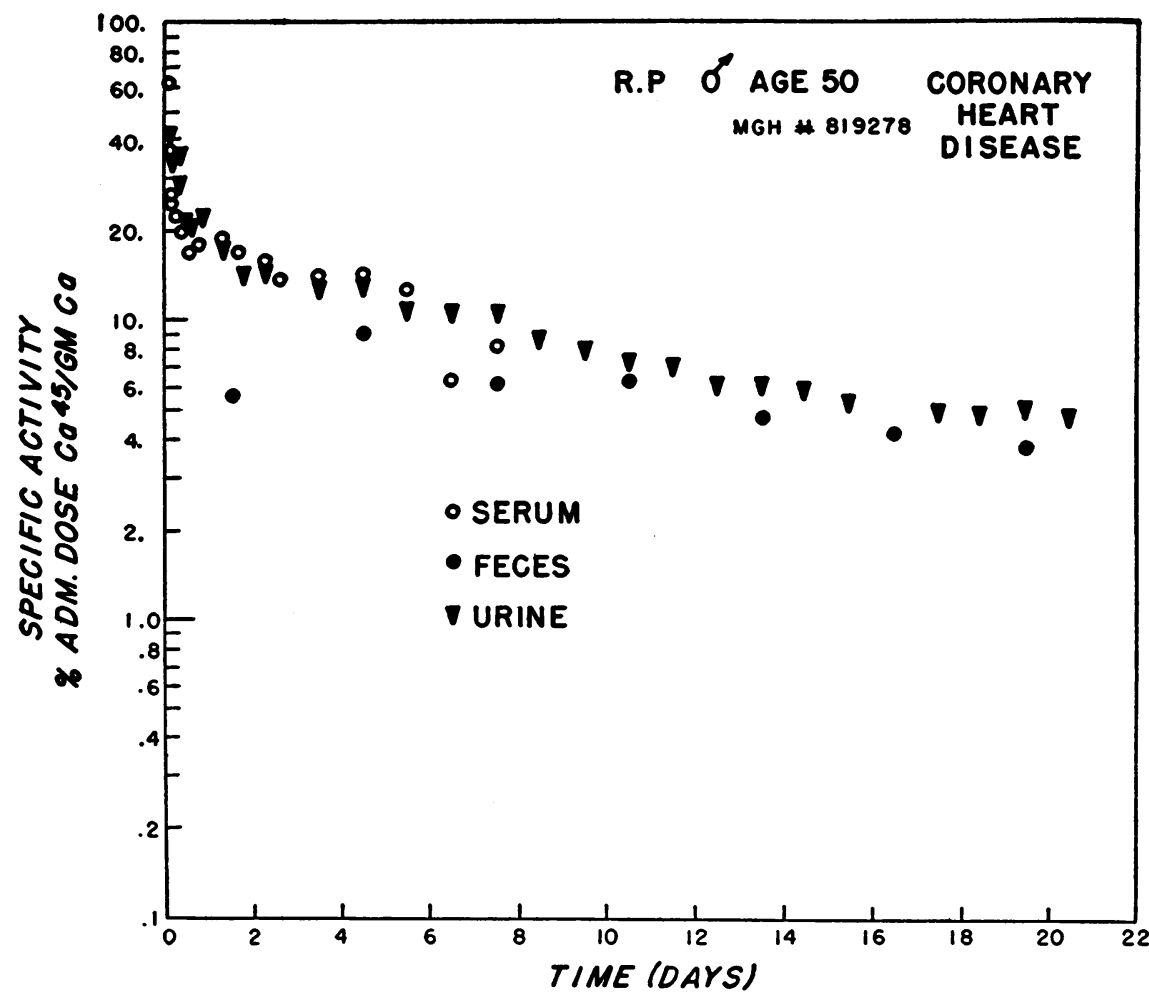

Fig. 2. Semi-Logarithmic Plot of Specific Activity Versus Time for the Data from Control Subject R. P. with Coronary Heart Disease

In this figure and Figures 3 to 5 the serum specific activity values for the first 30 minutes are not plotted.

decline in the specific activity curve. The analysis continues in the same manner into a third and, in some cases, a fourth compartment. The basic assumption of equal specific activities after equilibrium can be made in an open system (i.e., a system involving excretion of the substance) only when the amount being excreted is small compared to the other routes of flow to and from the compartments being studied. The data appear to validate these assumptions over the time interval studied. However, at longer times, the specific activity of the urine and blood may diverge markedly from that of the bone compartments because the flow from the large bone compartments may be small compared to the ingestion and excretion of unlabeled calcium.

\section{RESULTS}

\section{$C a^{45}$ data}

The concentration of labeled calcium in the serum declined rapidly following injection and could not be measured in most patients in the sample taken seven days after administration of the radioactive calcium. Within the first hour after injection. $\mathrm{Ca}^{45}$ appeared in the urine. Urine radio- activity was readily measurable throughout the period of study (9 to 21 days). There was no correlation between the total labeled calcium and the total stable calcium excreted over a 9-day period of observation (Table III).

Urine and serum specific activities yielded curves of characteristic form when plotted against time on semi-logarithmic paper (Figures 2-5). The specific activity of calcium in the serum was in all cases the same as that of the urine collection corresponding to the serum sample. Fecal specific activity was almost always less than that of the urine or serum sample in the midpoint of the collection period and fell off at a rate similar to that of urine.

In Figure 2 are plotted the data of a control subject (R. P.). An initial rapid fall in specific activity of blood and urine was followed by a slower, linear decline from the second to the eighteenth day after administration of $\mathrm{Ca}^{45}$. In contrast, the curve of specific activity of the hyperthyroid sub- 
ject (F. W., Figure 3) showed a more rapid fall to lower levels. In the subject with myxedema (W. W., Figure 4) there was a very slow fall in specific activity following the rapid initial decline. In subject A. W. (Figure 5) with Paget's disease, the drop in specific activity was very fast for the first eight days. The curve declined more slowly during the remaining 14-day period of observation.

Values for coefficients, rate constants and their standard deviations appear in Table IV. Differences among patients were most marked in the third slope which appeared by the second day. The small standard deviation of the slope and intercept of this function derived by least squares supports the supposition that the data are exponential in nature. In the two control patients (R. P. and Wa. W.) this slope was 0.081 per day, and 0.164 per day, respectively. Blau, Spencer, Swernov, and Laszlo (11) studied two patients without bone disease with radiocalcium in whom the slope of the function corresponding to $k_{3}$ was calculated to be 0.092 per day. In the hyperthy- roid subjects, $k_{3}$ ranged from 0.215 to 0.288 per day. When one of the thyrotoxic subjects was restudied four months after thyroidectomy, this third slope had decreased to 0.150 per day. In two female patients with myxedema of several years' duration, these values were 0.063 and 0.072 per day. Then metabolic rates were returned to normal with desiccated thyroid. Five months later, the values for $k_{8}$ were found to have risen to 0.150 and 0.174 , respectively.

Dimensions of the various compartments also appear in Table IV. The size of all compartments, especially the third, was greatest in the hyperthyroid subjects and those with Paget's disease. Compartments were smallest in the subjects with untreated myxedema and in subject $E$. N. with hypoparathyroidism.

The values for the calcium "pool" at nine days after administration of $\mathrm{Ca}^{45}$ are in Table III. Hyperthyroid subjects and those with Paget's disease had the largest "pools". These ranged from 47 to 333 grams. The myxedematous subjects and the

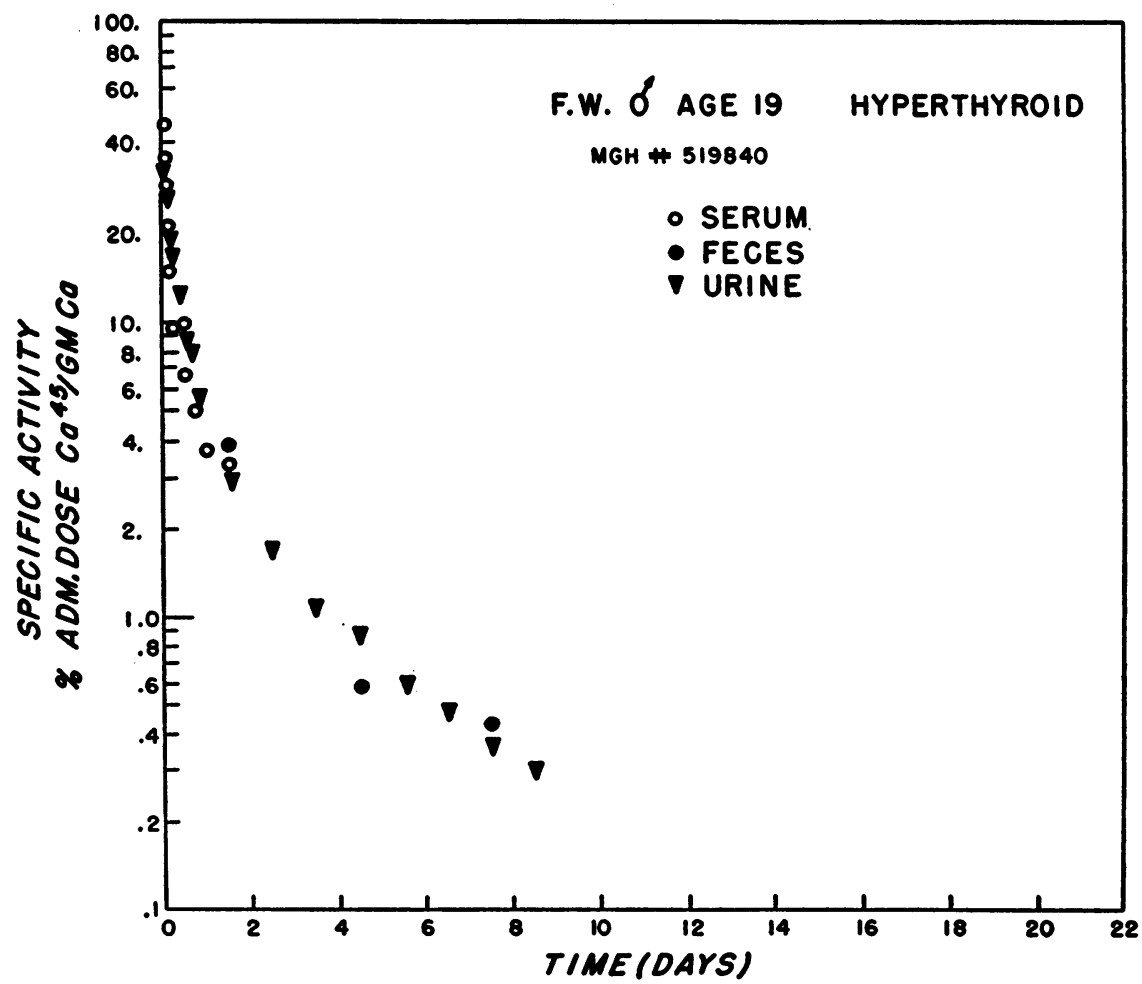

Fig. 3. Semi-Logarithmic Plot of Specific Activity Versus Time for SUBJECT F. W.(1) WITH HYPERTHYROIDISM

Observations were made for nine days following the administration of $\mathrm{Ca}^{\mathrm{w}}$. 


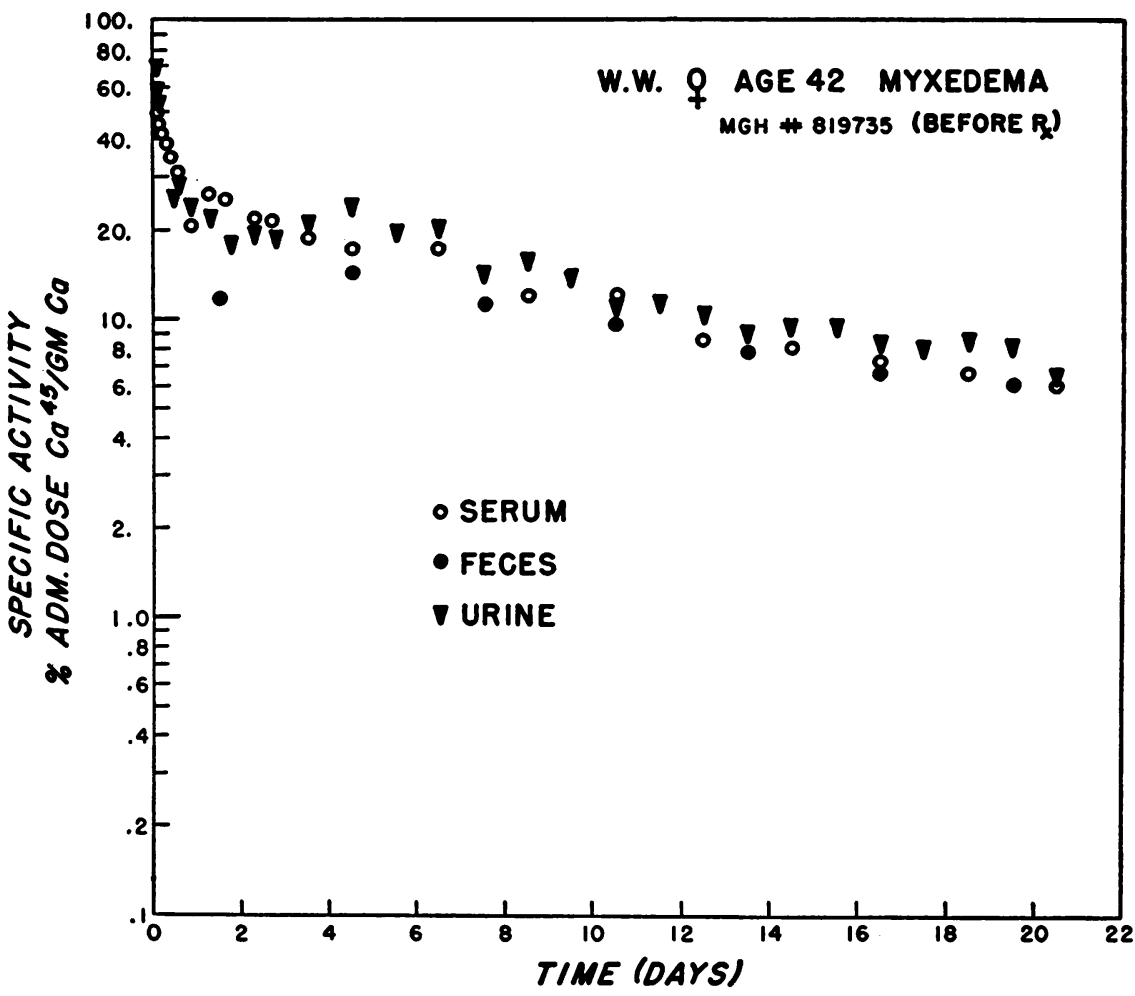

Fig. 4. Semi-Logarithmic Plot of Specific Activity Versus Time for the Data from Subject W. W.(1) with MyXedema before Treatment

patient with long-standing hypoparathyroidism had the smallest, 5.1, 5.0, and 4.4 grams, respectively. After treatment of the myxedema, the calcium "pool" rose to 13 and 18 grams. The rapidity and extent to which labeled calcium enters body calcium spaces in hyperthyroid, euthyroid, and myxedematous subjects is illustrated in the calcium "pool" curves of Figure 6.

\section{Balance data}

Metabolic balance data for calcium, phosphorus, and nitrogen are given in Table II. Two of the four hyperthyroid patients (F. W. and J. B.) were in a distinctly more negative calcium and phosphorus balance than is normal for a low calcium intake. Both had high levels of calcium in the feces as well as in the urine. Both had elevated urinary excretion of nitrogen, but their intakes were high in nitrogen and calories. They remained almost in nitrogen equilibrium and maintained their body weight. The other two hyperthyroid subjects, both female, had normal urinary calcium values and were in only slightly negative calcium balance. ${ }^{7}$ Alkaline phosphatase values in the serum were significantly elevated in patient F. W.(1), but there was no clinical evidence of liver disease, and there was no retention of bromsulphalein in the serum.

Urinary calcium excretion was low in both women with myxedema of long standing (B. M.(1) and $\left.W . W_{\cdot(1)}\right)$. The amount of calcium in the feces was normal. These subjects were in slightly negative calcium balance. Both were restudied five months after treatment with desiccated thyroid. Urinary calcium excretion had increased almost threefold, and total calcium excretion approximately doubled. The concentration of calcium and phosphorus in the serum was normal before and after treatment.

Subject L. S. went from negative calcium balance when she was hyperthyroid to positive balance five months after thyroidectomy, when signs of early myxedema were present. Urinary calcium, which had been $0.13 \mathrm{gm}$. per day when she

${ }^{7}$ Normal subjects are in slightly negative calcium balance on a low calcium intake (12). 
was hyperthyroid, averaged $0.02 \mathrm{gm}$. per day in the myxedematous state.

Patient E. N, with untreated surgical hypoparathyroidism of four years' duration had low urinary calcium levels. Fecal calcium values were high, presumably because during the period of study she continued to take eight enteric coated aspirin tablets per day. These were found subsequently to contain a total of $0.254 \mathrm{gm}$. calcium. It is possible that this calcium was not available for absorption. Patient F. W., the hyperthyroid subject who demonstrated the most marked calcium losses, became parathyroid following thyroid surgery. Although euthyroid when studied one year later, he still had evidence of parathyroid underactivity. He was in positive calcium balance of considerable degree at this time.

\section{DISCUSSION}

The nature of the processes governing uptake by the skeleton of labeled calcium and phosphorus has been studied by microradioautography and comparative $\mathrm{x}$-ray photography. Engfeldt, Eng- ström, and Zetterström (13) have shown that $P^{82}$ is deposited in cortical bone in discrete locations corresponding to individual Haversian systems. Radioactivity was most intense in those osteons of least density by $\mathrm{x}$-ray and therefore of most recent origin. In similar studies employing $\mathrm{Ca}^{45}$, Lacroix (14) also demonstrated that radioactivity is detected in compact bone only where osteogenesis is taking place, i.e., in the absorption cavities which are being filled by concentric lamellae of new bone. Lacroix (14) also demonstrated that in this regard cancellous bone behaves like compact bone. In addition, there is evidence that in vitro ion exchange and recrystallization processes occur to a greater extent in bone crystals from areas of recent origin than in older established bone (15).

The present study provides further information on the mobility and deposition of the calcium stores of the body as disclosed by observations on the progressive dilution of administered labeled calcium into the calcium compartments. Mixing in the first compartment $\left(Q_{1}\right)$ of dilution accounts

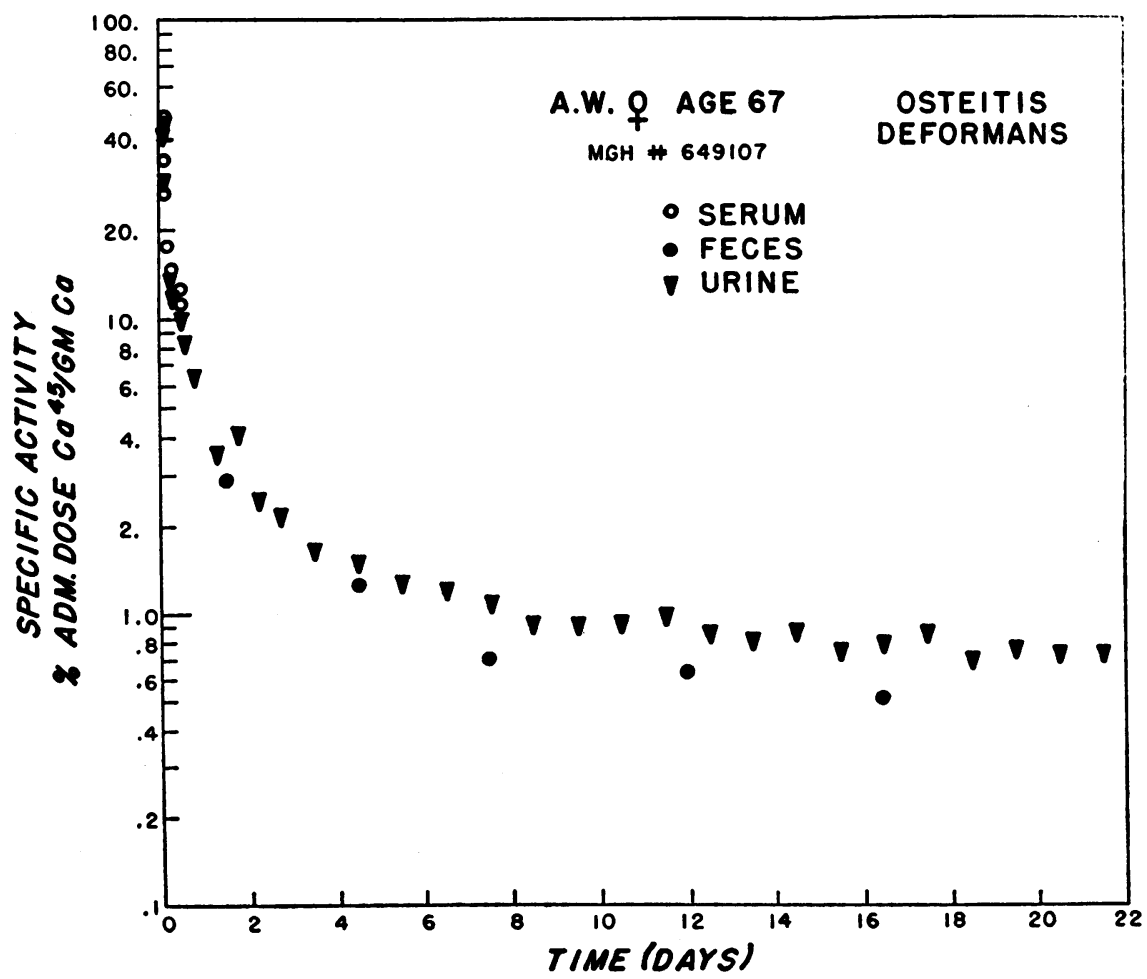

Fig. 5. Semi-Logarithmic Plot of Specific Activity Versus Time for the Data from Subject A. W. with Extensive Paget's Disease of Bone 


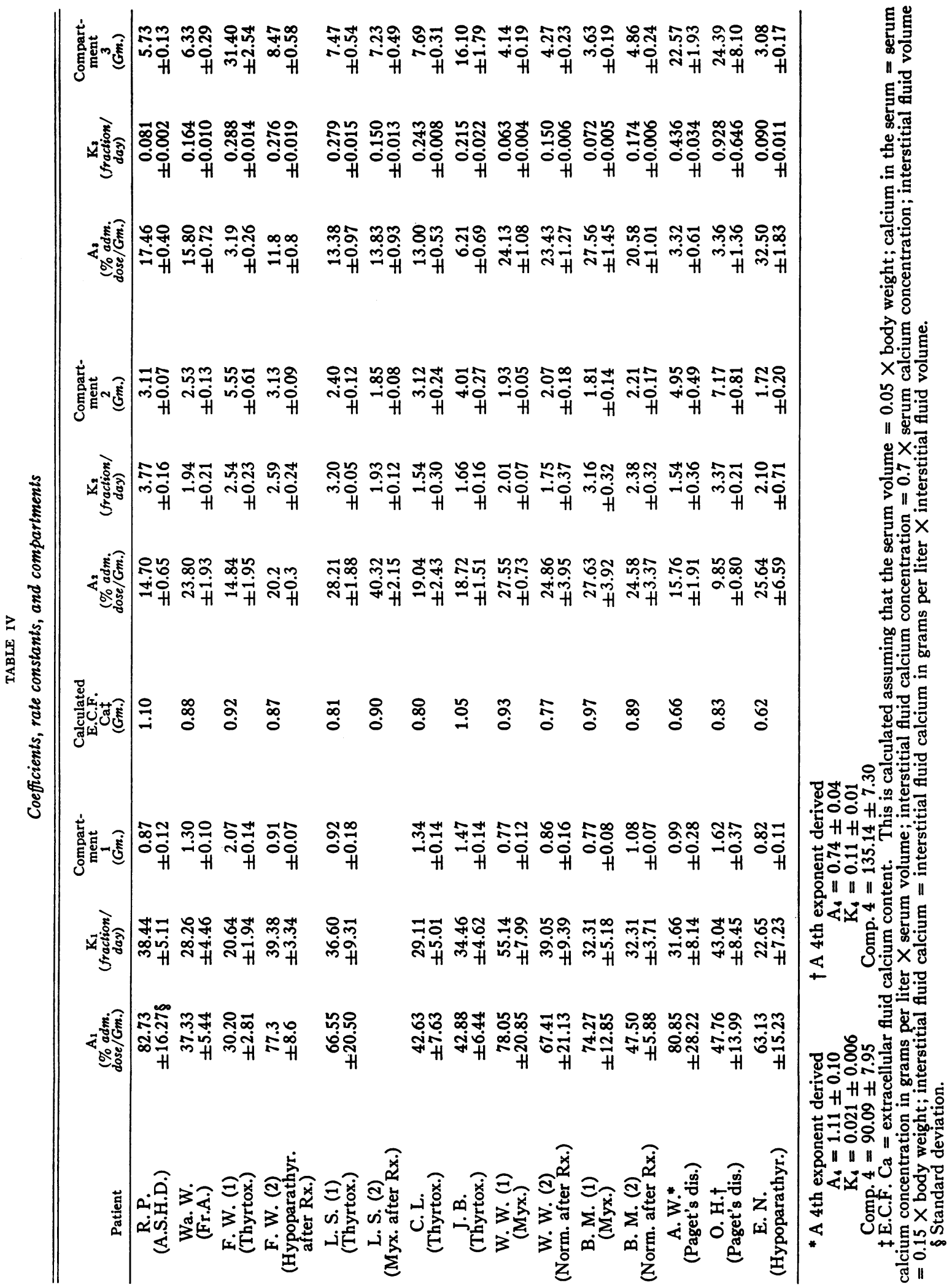




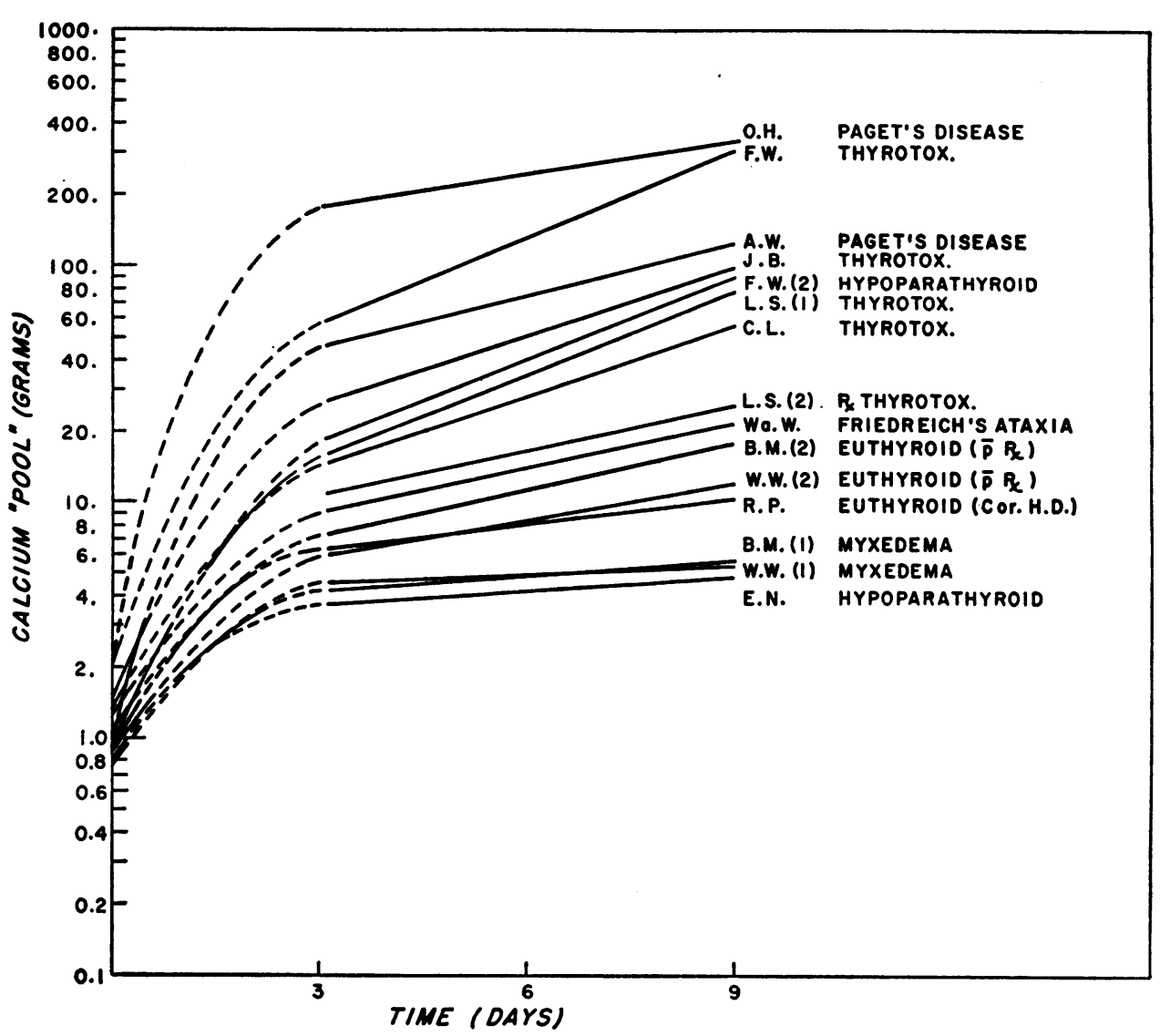

Fig. 6. Calcium "Pool" in Grams $\left(\frac{\% \text { Remaining in Body at Time } t}{\text { Specific Activity at Time } t}\right)$ is Plotted SemiLogarithmically Versus Time

It is apparent that $\mathrm{Ca}^{45}$ in the hyperthyroid subjects exchanges with a larger quantity of calcium and more rapidly than normal.

for the initial rapid fall in serum specific activity of labeled calcium after intravenous administration. In view of the small size of this compartment and its high rate constant it probably represents extracellular fluid. In support of this assumption is the close agreement of the calculated values of calcium content of the extracellular fluid and those obtained from analysis of the curve of isotope dilution (Table IV). An insufficient number of blood samples were drawn in the first 30 minutes after injection of labeled calcium to distinguish between serum and interstitial fluid distribution.

The second and third compartments reflect reversible processes. Flow rates from the first to the second $\left(k_{1} Q_{1}\right)$ and from the second to the third $\left(k_{2}\left[Q_{1}+Q_{2}\right]\right)$ are of too great a magnitude to be explained by an irreversible skeletal deposition of calcium salts, but are in keeping with ion ex- change at the surface of bone crystals and equilibration of surface ions with those in the crystal interior, i.e., recrystallization (15). Formation of new bone crystals incorporating the labeled calcium is consistent with flow $\left(k_{3}\left[Q_{1}+Q_{2}+Q_{3}\right]\right)$ from the third compartment. Whatever their exact significance, the compartments and flow rates observed were sensitive to varying levels of thyroid gland function.

In all patients studied the exchange between the calcium in the extracellular fluid and that in bone was very rapid. Nevertheless, the concentration of stable calcium in the blood (and extracellular fluid) remained quite constant. The quantity of calcium exchanged was far greater than the net quantity of calcium transferred from the bone to the extracellular fluid. In those subjects in negative balance, the net calcium lost (excreted) 
from the extracellular fluid was then rapidly replaced from the larger bone pools. This suggests part of the mechanism whereby serum levels can be maintained and controlled.

In all four hyperthyroid subjects the size of the calcium compartments and the rates of flow from these compartments were distinctly greater than in the euthyroid controls. This indicates increased osteogenesis. Calculation of the rate of calcium "accretion" from the data obtained in the present study by the method of Bauer, Carlsson, and Lindquist (16) supports this concept. Since these patients were in negative calcium balance on a low calcium intake, bone destruction as well as bone formation was proceeding at an increased rate. In myxedema, there was a slower rate of these processes. When myxedema was treated, the rate of fall of specific activity and the size of the compartments increased.

In hyperthyroidism, excessive destruction of bone may be the primary event. In addition, under the conditions of the present study, there may have been increased bone resorption in response to the low dietary intake of calcium. However, the weakened bones were able to respond with an increase in osteoblastic activity followed by deposition of mineral. This is what is pictured to occur in "osteitis fibrosa." Askanazy and Rutishauser (17) and, later, Follis (18) reported microscopic evidence of bone destruction in patients dying with hyperthyroidism. In Follis' series of 20 patients, osteitis fibrosa was found in the vertebral bodies of all, whereas osteoporosis was observed only in four subjects. These findings are thus not compatible with the concept that the primary bone disease of thyrotoxicosis is osteoporosis, defined as decreased bone formation from a failure of matrix formation, with bone destruction proceeding at a normal rate (19). The elevated concentration of alkaline phosphatase in the serum of patient F. W. when thyrotoxic also supports the concept of increased bone formation and is consistent with reported observations in other hyperthyroid patients (20) and the finding of increased bone phosphatase.in animals given excessive doses of thyroid (21).

It is possible that nutritional or other factors may adversely affect bone formation in other patients with hyperthyroidism. All in the present study were adults. Those females with abnormal thyroid function were pre-menopausal. Age may have been a factor in that the younger individuals studied here conceivably had a greater capacity to respond with an increase in osteogenesis. The two hyperthyroid subjects, F. W. and J. B., who were in the most negative calcium balance, were nearly in nitrogen equilibrium. This fact is contrary to the view that the hypercalcuria of hyperthyroidism is directly related to nitrogen losses (22).

The turnover of calcium in the bones may be related to blood flow. For this reason, two patients with Paget's disease of bone were studied. Often in osteitis deformans there is an increase in cardiac output and bone blood flow (23). The increase in vascularity could involve a greater exposure of bone crystals to $\mathrm{Ca}^{45}$ in circulating fluids and thereby increase the exchangeable surface. Both patients demonstrated an increased skeletal turnover of calcium. Both had extensive disease and elevation of the serum concentration of alkaline phosphatase. Increase in the vascularity of the skeleton in hyperthyroidism could influence skeletal uptake in the same direction, whereas decreased vascularity could have the opposite effect in myxedema. Blood flow in other organs is known to be decreased in myxedema (24).

Relief of the hypothyroid state was followed by a decreased turnover of skeletal calcium. Patient F. W., who demonstrated marked calcium losses and rapid turnover of skeletal calcium when hyperthyroid, still showed a rapid fall in specific activity one year after thyroidectomy, when euthyroid but hypoparathyroid. At the time of the second study, the size of the calcium compartments was much smaller and the calcium "pool" at nine days considerably decreased compared to the initial study. Nevertheless, the values were higher than expected by comparison to other subjects studied. It is possible that this patient had not remineralized his bones completely at the time of the second study.

Similarly, the hyperthyroid subject, L. S., restudied when myxedematous four months after thyroidectomy, showed a decrease by a factor of two in rates of flow of calcium in and out of the osseous compartments, but the values were then about the same as the euthyroid controls. At the same time, urinary and fecal calcium excretion were reduced by a factor of four. This implies 
that after withdrawal of the thyroid hormone, a decrease in the rate of bone destruction occurs sooner than a decrease in osteogenesis.

The effects of thyroid hormone are probably not mediated by the parathyroids. Aub, Albright, Bauer, and Rossmeisl (4) demonstrated that thyroid increases the serum and urinary calcium in patients with idiopathic and surgical hypoparathyroidism. Cope and Donaldson (5) reported a patient who developed hypocalcemia and tetany following an inadequate subtotal thyroidectomy for hyperthyroidism. When hyperthyroidism recurred, tetany was relieved and the concentration of calcium in the serum rose. Hypocalcemia and tetany again appeared after treatment with potassium iodide.

Increased fecal calcium in two patients with hyperthyroidism and the very low fecal calcium in one of the myxedematous subjects (L. S.(2) ) are in keeping with the earlier reports of Aub, Bauer, Heath, and Ropes (1) and are contrary to the concept proposed by Robertson (25) that the primary effect of the thyroid hormone on calcium metabolism is on the kidney alone. The finding of hypercalcuria, often extreme in some patients with hyperthyroidism, in the presence of normal serum calcium suggests either an increase in filtered load or decreased tubular reabsorption.

\section{SUMMARY AND CONCLUSIONS}

1. Radioactive calcium $\left(\mathrm{Ca}^{45}\right)$ was given intravenously to patients with hyperthyroidism and myxedema. Euthyroid subjects and patients with Paget's disease of bone, and others with hypoparathyroidism were similarly studied. Several patients were studied before and after appropriate treatment. Total quantities of the isotope excreted and specific activities of the serum, urine, and feces were determined frequently for 9 to 22 days. In addition, stable calcium, phosphorus, and nitrogen balances were performed on each subject.

2. In four subjects with hyperthyroidism, specific activity of serum and urine declined more rapidly and to lower levels than in euthyroid controls. In contrast, two myxedematous patients demonstrated the least fall in specific activity. After five months of treatment of the myxedema specific activity curves were found to decline at the same rate as in the control patients.
3. Observation of all the specific activity curves suggests that they can be analyzed into a series of decreasing exponential functions. It is proposed that each function represents a discrete calcium compartment within the body.

4. Changing thyroid function modifies the size of the calcium compartments and the rate of flow to and from these compartments. Compartment sizes and flow rates are greatest in hyperthyroidism and Paget's disease of bone and least in myxedema.

5. Two of four hyperthyroid subjects were in nitrogen equilibrium, despite which they showed marked losses of calcium in the urine and feces.

6 . The findings indicate that bone formation as well as destruction are proceeding at increased rates in thyrotoxicosis.

\section{REFERENCES}

1. Aub, J. C., Bauer, W., Heath, C., and Ropes, M., Studies of calcium and phosphorus metabolism. III. The effects of the thyroid hormone and thyroid disease. J. Clin. Invest., 1929, 7, 97.

2. Albright, F., Bauer, W., and Aub, J. C., Studies of calcium and phosphorus metabolism. VIII. The influence of the thyroid gland and the parathyroid hormone upon the total acid-base metabolism. J. Clin. Invest., 1931, 10, 187.

3. Tibbetts, D. M., McLean, R., and Aub, J. C., Studies of calcium and phosphorus metabolism. XX. The high calcium excretion in exophthalmic goiter is not due to vitamine $\mathrm{D}$ deficiency. J. Clin. Invest., 1932, 11, 1273.

4. Aub, J. C., Albright, F., Bauer, W., and Rossmeisl, E., Studies of calcium and phosphorus metabolism. VI. In hypoparathyroidism and chronic steatorrhea with tetany with special consideration of the therapeutic effect of thyroid. J. Clin. Invest., 1932, 11, 211.

5. Cope, O., and Donaldson, G. A., Relation of thyroid and parathyroid glands to calcium and phosphorus metabolism. Study of a case with coexistent hypoparathyroidism and hyperthyroidism. J. Clin. Invest., 1937, 16, 329.

6. Golden, R., and Abbott, H., The relation of the thyroid, the adrenals and the islands of Langerhans to malacic diseases of bone. Am. J. Roentgenol., 1933, 30, 641 .

7. Armstrong, W. D., Radiotracer studies of hard tissues. Ann. New York Acad. Sc., 1955, 60, 670.

8. Bronner, F., Harris, R. S., Maletskos, C. J., and Benda, C. E., Studies in calcium metabolism. The fate of intravenously injected radiocalcium in human beings. J. Clin. Invest., 1956, 35, 78.

9. Fiske, C. H., and Logan, M. A., The determination of calcium by alkalimetric titration. II. The pre- 
cipitation of calcium in the presence of magnesium, phosphate, and sulfate, with applications to the analysis of urine. J. Biol. Chem., 1931, 93, 211.

10. Fiske, C. H., and Subbarrow, Y., The colorimetric determination of phosphorus. J. Biol. Chem., 1925, 66, 375.

11. Blau, M., Spencer, H., Swernov, J., and Laszlo, D., Utilization and intestinal excretion of calcium in man. Science, 1954, 120, 1029.

12. Bauer, W., Albright, F., and Aub, J. C., Studies of calcium and phosphorus metabolism. II. The calcium excretion of normal individuals on a low calcium diet, also data on a case of pregnancy. J: Clin. Invest., 1929, 7, 75.

13. Engfeldt, B., Engström, A., and Zetterström, R., Renewal of phosphate in bone minerals. II. Radioautographic studies of the renewal of phosphate in different structures of bone. Biochim. et Biophys. Acta, 1952, 8, 375.

14. Lacroix, P., Radiocalcium and radiosulphur in the study of bone metabolism at the histological level in Proceedings of 2nd Radioisotope Conference, Oxford, 1954, New York, Academic Press, 1954, N. 1, p. 134.

15. Neuman, W. F., and Newman, M. W., The nature of the mineral phase of bone. Chem. Rev., 1953, $53,1$.

16. Bauer, G. C. H., Carlsson, A., and Lindquist, B., Evaluation of accretion, resorption, and exchange reactions in the skeleton. Kungl. Fysiografiska Sällskapet, Lund Förhandlingar, 1955, 25, 1.

17. Askanazy, M., and Rutishauser, E., Die Knochen der Basedow-Kranken. Beitrag zur latenten Osteo- dystrophia fibrosa. Virchows Arch. f. path. Anat., 1933, 291, 653.

18. Follis, R. H., Jr., Skeletal changes associated with hyperthyroidism. Bull. Johns Hopkins Hosp., 1953, 92, 405.

19. Albright, F., and Reifenstein, E. C., Jr., The Parathyroid Glands and Metabolic Bone Disease; Selected Studies. Baltimore, Williams \& Wilkins Co., 1948.

20. Nielsen, $\mathbf{H}$., The bone system in hyperthyroidism. A clinical and experimental study. Acta med. Scandinav., 1952, 142, Supp. 266, 783.

21. Williams, H. L., and Watson, E. M., Influence of hormones upon phosphatase content of rat femurs. II. Effects of sex hormones, thyroxin, and thymus extract. Endocrinology, 1941, 29, 258.

22. Kinsell, L. W., Hertz, S., and Reifenstein, E. C., Jr., The effect of testosterone compounds upon the nitrogen balance and the creatine excretion in patients with thyrotoxicosis. J. Clin. Invest., 1944, 23, 880 .

23. Edholm, O. G., and Howarth, S., Studies on the peripheral circulation in osteitis deformans. Clin. Sc., 1953, 12, 277.

24. Rawson, R. W., and Rall, J. E., Diseases of the Thyroid in Duncan, G. G., Ed., Diseases of Metabolism, Detailed Methods of Diagnosis and Treatment, 3rd ed., Philadelphia, W. B. Saunders Company, 1952, p. 957.

25. Robertson, J. D., Calcium and phosphorus excretion in thyrotoxicosis and myxoedema. Lancet, 1942, 1, 672. 